\title{
Tunable Metal-Organic Frameworks Enable High Efficiency Cascaded Adsorption Heat Pumps
}

Authors: Adam J. Rieth ${ }^{1}$, Ashley M. Wright ${ }^{1}$, Sameer Rao ${ }^{2}$, Hyunho Kim $^{2}$, Alina D. LaPotin ${ }^{2}$, Evelyn N. Wang ${ }^{2}$, Mircea Dincă ${ }^{1 *}$

\author{
Affiliations: \\ ${ }^{1}$ Department of Chemistry, Massachusetts Institute of Technology, 77 Massachusetts Ave. \\ Cambridge, Massachusetts, 02139, United States. \\ ${ }^{2}$ Department of Mechanical Engineering, Massachusetts Institute of Technology, 77 \\ Massachusetts Ave. Cambridge, Massachusetts, 02139, United States.
}

\section{Summary}

Rising global standards of living coupled with the recent agreement to eliminate hydrofluorocarbon refrigerants are creating intense pressure to develop more sustainable climate control systems. In this vein, the use of water as the refrigerant in adsorption heat pumps is highly attractive, but such adsorption systems are constrained to large size and poor efficiency by the characteristics of currently employed water sorbents. Here we demonstrate control of the relative humidity of water uptake by modulating the pore size in a family of isoreticular triazolate metalorganic frameworks. Using this method, we identify a pair of materials with stepped, nonoverlapping water isotherms that can function in tandem to provide continuous cooling with a record ideal coefficient of performance of 1.63. Additionally, when used in a single-stage heat pump, the microporous $\mathrm{Ni}_{2} \mathrm{Cl}_{2} \mathrm{BBTA}$ has the largest working capacity of any material capable of generating a $25^{\circ} \mathrm{C}$ difference between ambient and chiller output.

\section{Introduction}

More than $44 \%$ of all primary energy in the U.S. residential and commercial sectors is consumed by climate control systems.[1] Globally, as standards of living in the developing world rise, the resultant rapid growth in demand for air conditioning is a major driver of increased worldwide electricity consumption.[2] Thermally-driven cooling cycles, such as adsorption heat pumps (AHPs), can utilize previously wasted energy resources such as engine exhaust, waste heat from power generation, or chemical process heat, resulting in dramatic reductions in primary energy consumption for heating and cooling. [3-5] Interest in AHPs using water as the refrigerant has spiked in light of the recent agreement to phase out hydrofluorocarbons, the refrigerants most commonly employed in conventional vapor compression heat pumps, due to their very high global warming potential.[6-8]

Widespread deployment of AHPs is limited by shortcomings of the currently employed active sorbents, including low water capacity and shallow water uptake step profiles that are not tunable as a function of relative humidity $(\mathrm{RH}) .[3,9-12]$ These shortcomings result in bulky devices which suffer from low thermal efficiency. In principle, the efficiency of AHP systems, as measured by the coefficient of performance (COP, defined as the cooling energy per unit energy input), could be improved by employing multiple-effect cascaded cycles wherein two or more adsorbent beds are operated in series.[13] Cascaded 

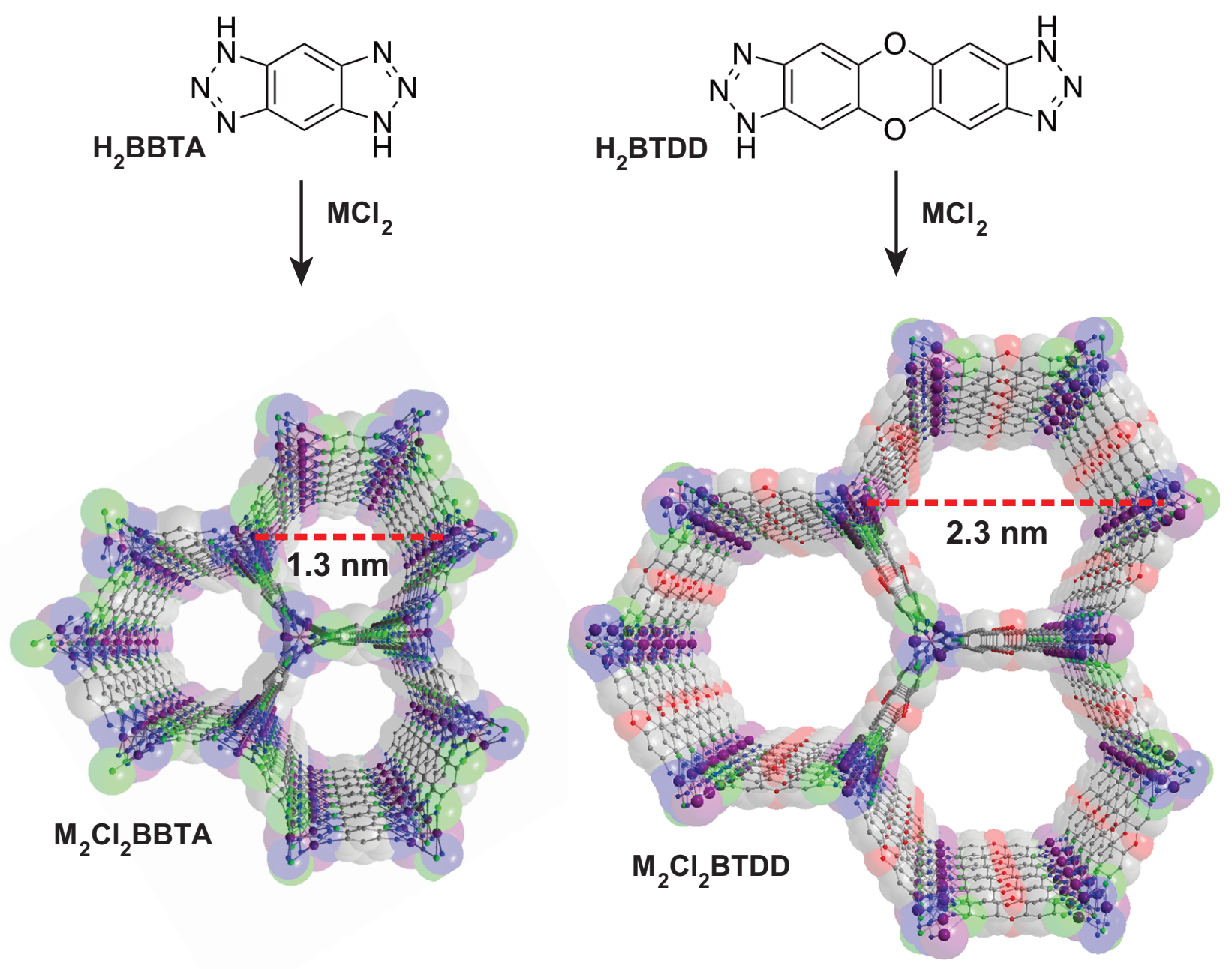

Figure 1: Synthetic route and structure depiction of $\mathrm{M}_{2} \mathrm{Cl}_{2} \mathrm{BBTA}$ and $\mathrm{M}_{2} \mathrm{Cl} \mathrm{l}_{2} \mathrm{BTDD}$. $\mathrm{C}$ - gray, $\mathrm{O}$ - red, $\mathrm{N}$ - blue, $\mathrm{Cl}$ - green, $\mathrm{M}$ - purple. For clarity, $\mathrm{H}$ atoms are omitted.

temperature stages allow for the reuse of input thermal energy at progressively lower temperatures in each successive bed, resulting in higher overall efficiency. For instance, a three-stage cascaded AHP using silica gel and activated carbon adsorbents can achieve a superb overall COP of 1 , but requires an elevated driving temperature of $220{ }^{\circ} \mathrm{C}$. [14] Further improvements require designing pairs of materials with water uptake steps tailored to fully reuse the excess energy from the high temperature stage with the low temperature stage. Such fine tuning in adsorbent design has not been possible so far.

In view of their recently demonstrated utility as sorbents in AHPs, $[4,9,10,15,16]$ metalorganic frameworks (MOFs) are poised to offer thermodynamically matched material pairs that would enable record performance in cascaded systems. In addition to higher overall capacity, MOFs typically exhibit steeper uptake steps, occurring in a narrow RH range, which directly improve efficiency because cycling between the filled state and the empty state requires a minimal temperature swing.[17] Most importantly for cascaded AHPs, MOFs allow for precise control over the position of water uptake as a function of RH. [11,18-25] This is vital because it determines the maximum temperature difference (lift) an AHP system can produce and defines the required driving temperature to regenerate the sorbent.[9] More hydrophilic sorbents will adsorb water at lower $\mathrm{RH}$, and can produce a 
higher lift, but will also require a higher temperature heat source for regeneration because water is adsorbed more strongly. Therefore, the ideal sorbent is one whose hydrophilicity provides enough driving force to achieve the target temperature lift, but is not so high as to decrease thermal efficiency.[9,16]

We recently reported a MOF, $\mathrm{Co}_{2} \mathrm{Cl}_{2} \mathrm{BTDD}$ (BTDD $=$ bis $(1 H-1,2,3$-triazolo[4,5b],[4',5'-i])dibenzo[1,4]dioxin) whose pore size allows water sorption at the uptake reversibility limit.[16,26] $\mathrm{Co}_{2} \mathrm{Cl}_{2} \mathrm{BTDD}$ is the best-performing sorbent for single-stage AHPs capable of a $20^{\circ} \mathrm{C}$ lift. $[9,16]$ Here we show that a smaller-pore isoreticular MOF made from the shorter bistriazolate linker $1 H, 5 H$-benzo(1,2-d),(4,5-d')bistriazole (BBTA)[27,28] is significantly more hydrophilic and enables a lift greater than $40{ }^{\circ} \mathrm{C}$, which, in combination with the larger pore system, can enable a record high-efficiency $(\mathrm{COP}>1)$ cascaded double-effect AHP system.

\section{Results}

Water vapor adsorption isotherms measured at $298 \mathrm{~K}$ for activated samples of $\mathrm{M}_{2} \mathrm{Cl}_{2} \mathrm{BBTA}(\mathrm{M}=\mathrm{Co}, \mathrm{Ni}, \mathrm{Cu})$ are shown in Figure 2. All three materials exhibit type $\mathrm{I}$ isotherms with pore filling at low $\mathrm{RH}$, attributed to coordination of water at the metal nodes, followed by further hydrogen bonding-assisted adsorption until pore saturation. The nickel and cobalt materials both adsorb nearly 30 percent water by weight (wt $\%$ ) below $5 \% \mathrm{RH}$. The copper analog exhibits a significantly lower water capacity, as well as an irreversible step at 30\% RH. Powder X-ray diffraction (PXRD) analysis and nitrogen adsorption experiments revealed that the copper material loses porosity and undergoes a phase change after water uptake (Figures S1 and S2). Similarly, the cobalt material largely maintains its crystallinity, but loses much of its porosity after reactivation upon water sorption (Figures S3 and S4). By contrast, the nickel MOF retains its crystallinity and porosity (Figures S5 and S6) even after water sorption and desorption. This stability trend is in line with that

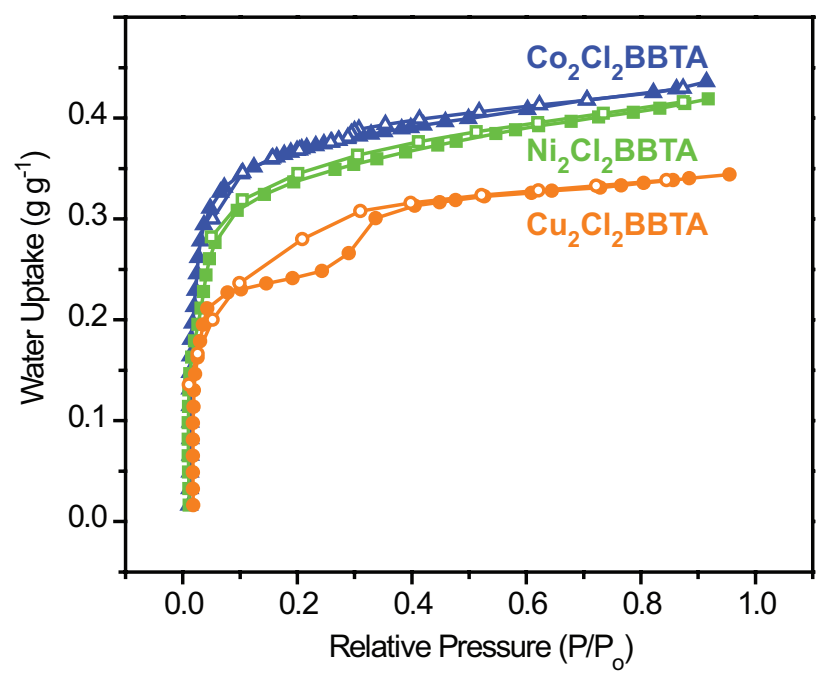

Figure 2: Water vapor isotherms for $\mathbf{M}_{2} \mathbf{C l}_{2}$ BBTA materials.

Adsorption (filled symbols) and desorption (open symbols) at $298 \mathrm{~K}$ for $\mathrm{Co}_{2} \mathrm{Cl}_{2} \mathrm{BBTA}$ (blue triangles), $\mathrm{Ni}_{2} \mathrm{Cl}_{2} \mathrm{BBTA}$ (green squares, measured at $296 \mathrm{~K}$ ), and $\mathrm{Cu}_{2} \mathrm{Cl}_{2} \mathrm{BBTA}$ (orange circles). 
previously observed for ammonia sorption in this family of materials and is the result of the kinetics of ligand exchange at the metal ion.[29]

Due to its greater stability, $\mathrm{Ni}_{2} \mathrm{Cl}_{2} \mathrm{BBTA}$ would be the more appropriate choice for a cascaded AHP. The enthalpy of water adsorption $\left(\Delta H_{a d s}\right)$ in $\mathrm{Ni}_{2} \mathrm{Cl}_{2} \mathrm{BBTA}$, determined by variable temperature water vapor sorption isotherms (Figure S7), is approximately $55 \mathrm{~kJ}$ $\mathrm{mol}^{-1}$ at zero coverage, nearly identical to that found for water binding to the open coordination sites of $\mathrm{Co}_{2} \mathrm{Cl}_{2} \mathrm{BTDD}$ [16] (Figure S8). Importantly, during pore filling of $\mathrm{Ni}_{2} \mathrm{Cl}_{2} \mathrm{BBTA}, \Delta H_{\text {ads }}$ remains above $50 \mathrm{~kJ} \mathrm{~mol}^{-1}$, indicating stronger across-pore hydrogen bonding interactions, likely due to confinement effects,[30,31] than those found in the larger pore $\mathrm{Co}_{2} \mathrm{Cl}_{2} \mathrm{BTDD}$, wherein $\Delta H_{\text {ads }}$ during pore-filling is $46 \mathrm{~kJ} \mathrm{~mol}^{-1}$. The variabletemperature water vapor isotherms for $\mathrm{Ni}_{2} \mathrm{Cl}_{2} \mathrm{BBTA}$ were also used to validate a characteristic curve (Figure S9), which converts the two independent variables that govern uptake, vapor pressure and temperature, into a single parameter related to the Gibbs free energy of adsorption (see Supplementary Information)[9,15,16] and allows extrapolation of the water loading at any temperature and pressure (Figure S10).

\section{Single-Stage Heat Pump Using $\mathrm{Ni}_{2} \mathrm{Cl}_{2} \mathrm{BBTA}$}

The characteristic curve can be used to calculate water loadings in $\mathrm{Ni}_{2} \mathrm{Cl}_{2} \mathrm{BBTA}$ under conditions relevant for heat pump applications, which are in turn used to calculate the working capacity and COP. Under refrigeration II conditions (i.e. chiller output of $278 \mathrm{~K}$ and ambient of $303 \mathrm{~K}$ for $25^{\circ} \mathrm{C}$ lift), [9] $\mathrm{Ni}_{2} \mathrm{Cl}_{2} \mathrm{BBTA}$ has a maximum COP of 0.70 and a volumetric working capacity of nearly $0.40 \mathrm{~mL} \mathrm{H}_{2} \mathrm{O} \mathrm{mL}{ }^{-1} \mathrm{MOF}$ using a $400 \mathrm{~K}$ desorption temperature (Figure 3A, filled squares). This is the highest reported volumetric working capacity for any material working under Refrigeration II standardized conditions (i.e. capable of a $25^{\circ} \mathrm{C}$ lift). Notably, because of the exceptional hydrophilicity of $\mathrm{Ni}_{2} \mathrm{Cl}_{2} \mathrm{BBTA}$, the temperature lift it could achieve is primarily limited by the regeneration temperature
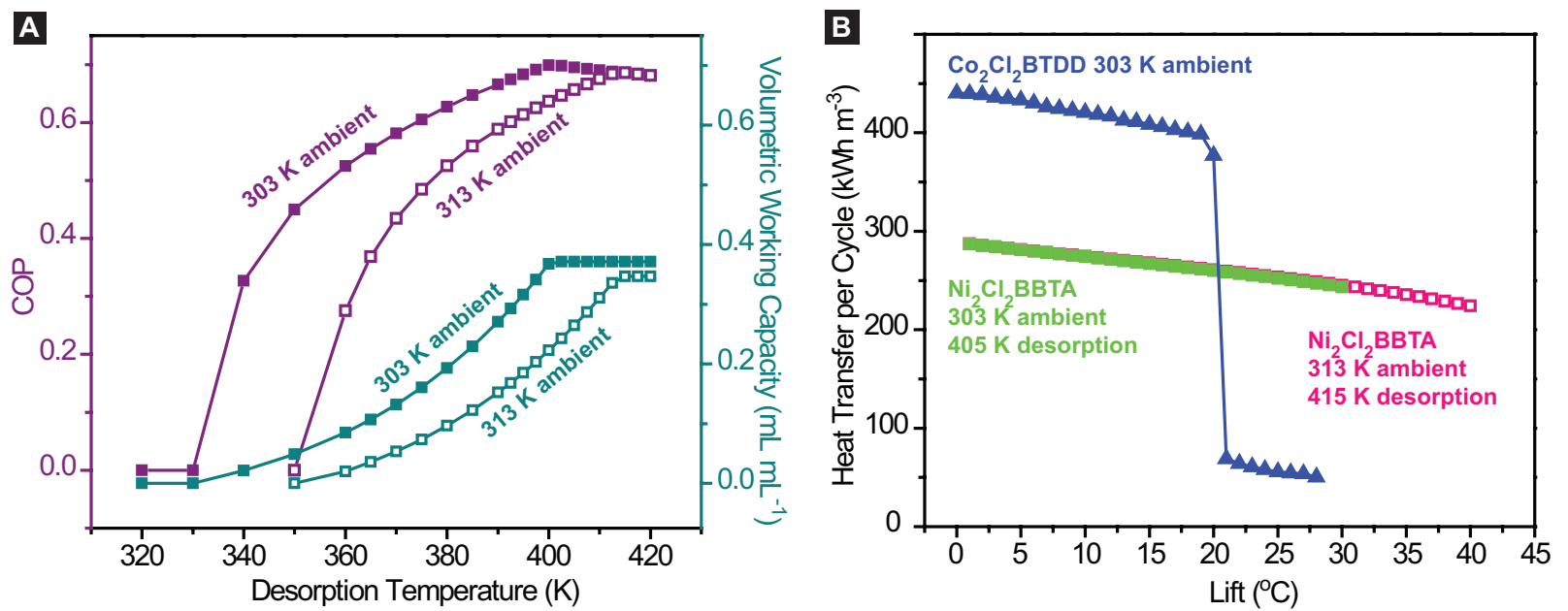

Figure 3: Single-stage heat pump figures of merit.

A) Coefficient of Performance (purple symbols, left axis) and volumetric working capacity (aqua symbols, right axis) for $\mathrm{Ni}_{2} \mathrm{Cl}_{2} \mathrm{BBTA}$ with a chiller output temperature of $278 \mathrm{~K}$ and an ambient temperature of either $303 \mathrm{~K}$ (filled symbols, $25^{\circ} \mathrm{C}$ lift) or $313 \mathrm{~K}$ (open symbols, $35^{\circ} \mathrm{C}$ lift) as a function of desorption temperature. B) Heat transferred per cycle, determined by varying the evaporator (output) temperature, versus temperature lift for $\mathrm{Ni}_{2} \mathrm{Cl}_{2} \mathrm{BBTA}$ (squares) and $\mathrm{Co}_{2} \mathrm{Cl}_{2} \mathrm{BTDD}$ (blue triangles). 
rather than the position of its water uptake step, which is otherwise dominant in other materials. For instance, if the ambient temperature increases to $313 \mathrm{~K}$, the water$\mathrm{Ni}_{2} \mathrm{Cl}_{2}$ BBTA working pair can still produce a $278 \mathrm{~K}$ chiller output $\left(35^{\circ} \mathrm{C}\right.$ lift $)$ with only minimal decreases in the COP and working capacity (Figure 3A , open squares). Further, with an ambient temperature of $30{ }^{\circ} \mathrm{C}(303 \mathrm{~K}), \mathrm{Ni}_{2} \mathrm{Cl}_{2} \mathrm{BBTA}$ can achieve a $30{ }^{\circ} \mathrm{C}$ lift (Figure 3B, filled green squares), and with an ambient temperature of $40{ }^{\circ} \mathrm{C}(313 \mathrm{~K})$ $\mathrm{Ni}_{2} \mathrm{Cl}_{2} \mathrm{BBTA}$ can achieve a $40^{\circ} \mathrm{C}$ lift with only a $10^{\circ} \mathrm{C}$ increase in desorption temperature (Figure 3B, open pink squares).

In agreement with the characteristic curve calculations, cycling of $\mathrm{Ni}_{2} \mathrm{Cl}_{2} \mathrm{BBTA}$ between $25^{\circ} \mathrm{C}$ and $150{ }^{\circ} \mathrm{C}$ at a constant vapor pressure of $4.76 \mathrm{mmHg}\left(20 \% \mathrm{RH}\right.$ at $25{ }^{\circ} \mathrm{C}$, well beyond the saturation $\mathrm{RH}$ value at this temperature) revealed an initial slight decline in uptake followed by a plateau at $0.36 \mathrm{~g} \mathrm{~g}^{-1}$ (Figure S11). We note that this is close to the vapor pressure of water ice at $0{ }^{\circ} \mathrm{C}, 4.585 \mathrm{mmHg}\left(\sim 20 \% \mathrm{RH}\right.$ at $\left.25^{\circ} \mathrm{C}\right)$. Impressively, nearly all of the capacity of $\mathrm{Ni}_{2} \mathrm{Cl}_{2} \mathrm{BBTA}$, greater than $0.33 \mathrm{~g} \mathrm{~g}^{-1}$, is reached below this vapor pressure (Figure 2). Although using water as the refrigerant makes it impossible to cool below $0{ }^{\circ} \mathrm{C}$, the unique behaviour of $\mathrm{Ni}_{2} \mathrm{Cl}_{2} \mathrm{BBTA}$ towards water vapour highlights its potential as a desiccant in other applications such as industrial compressed air drying that require sub-zero dewpoints.[32]

\section{Two-Stage Cascaded Heat Pump Using $\mathrm{Ni}_{2} \mathrm{Cl}_{2} \mathrm{BBTA}$ and $\mathrm{Co}_{2} \mathrm{Cl}_{2} \mathrm{BTDD}$}

In order to utilize the full potential driving force for heat transfer with $\mathrm{Ni}_{2} \mathrm{Cl}_{2} \mathrm{BBTA}$, we devised a concept tandem cascaded heat pump cycle (Figure 4A and 4B). Due to the material's exceptional affinity for water, water vapor can be adsorbed from a low temperature evaporator onto a bed of $\mathrm{Ni}_{2} \mathrm{Cl}_{2} \mathrm{BBTA}$ maintained between $104{ }^{\circ} \mathrm{C}$ and $57{ }^{\circ} \mathrm{C}$. When combined in a tandem cycle with a material exhibiting a lower affinity for water
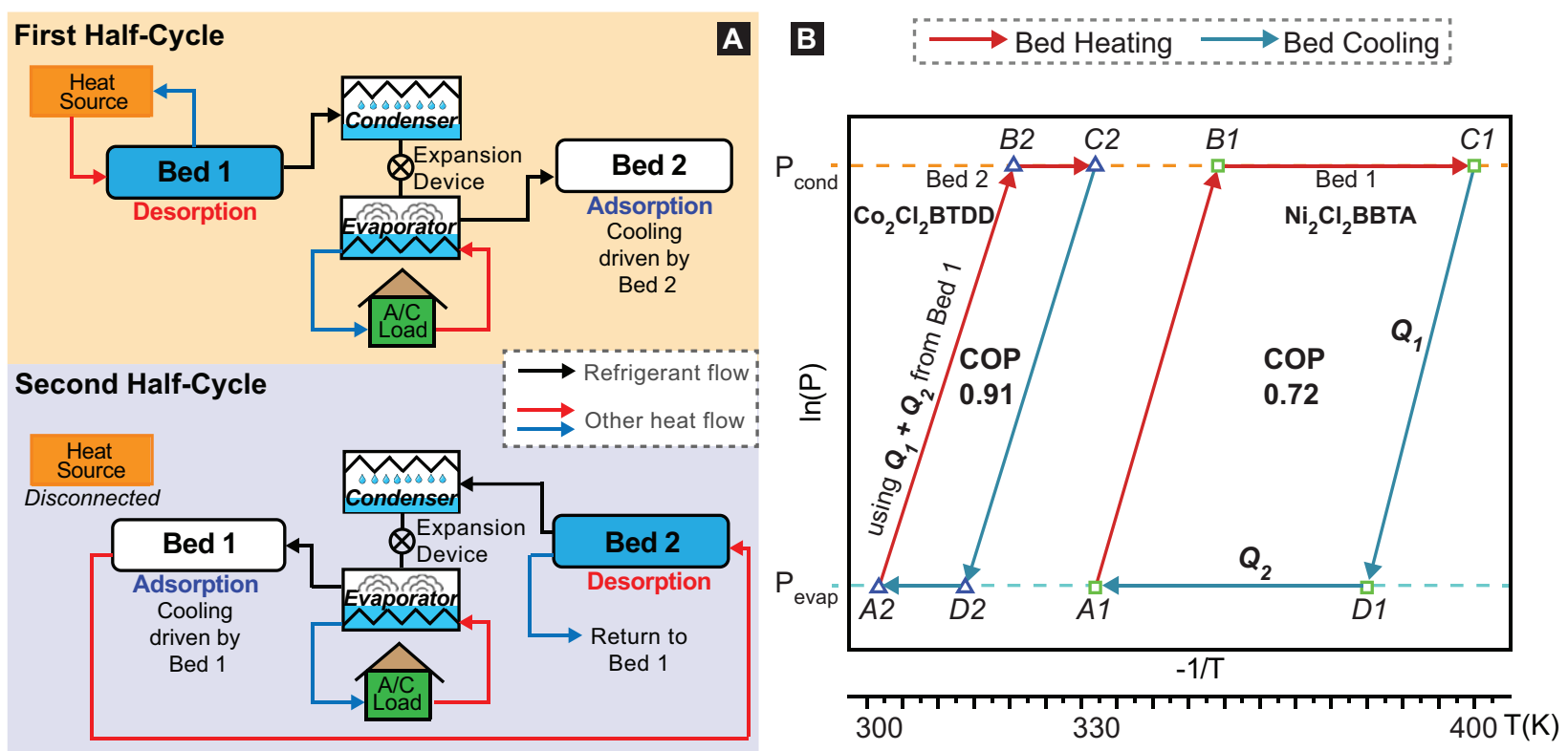

Figure 4: Two-stage cascaded heat pump cycle diagram and thermodynamics.

A) Schematic of a cascaded double-effect adsorption heat pump for stationary applications. B) Isosteric cycle diagram of a cascaded adsorption heat pump cycle providing a $17^{\circ} \mathrm{C}$ lift with evaporator at $283 \mathrm{~K}$, condenser at $300 \mathrm{~K}$, desorption of $\mathrm{Co}_{2} \mathrm{Cl}_{2} \mathrm{BTDD}$ at $330 \mathrm{~K}$ and desorption of $\mathrm{Ni}_{2} \mathrm{Cl}_{2} \mathrm{BBTA}$ at $400 \mathrm{~K}$. 

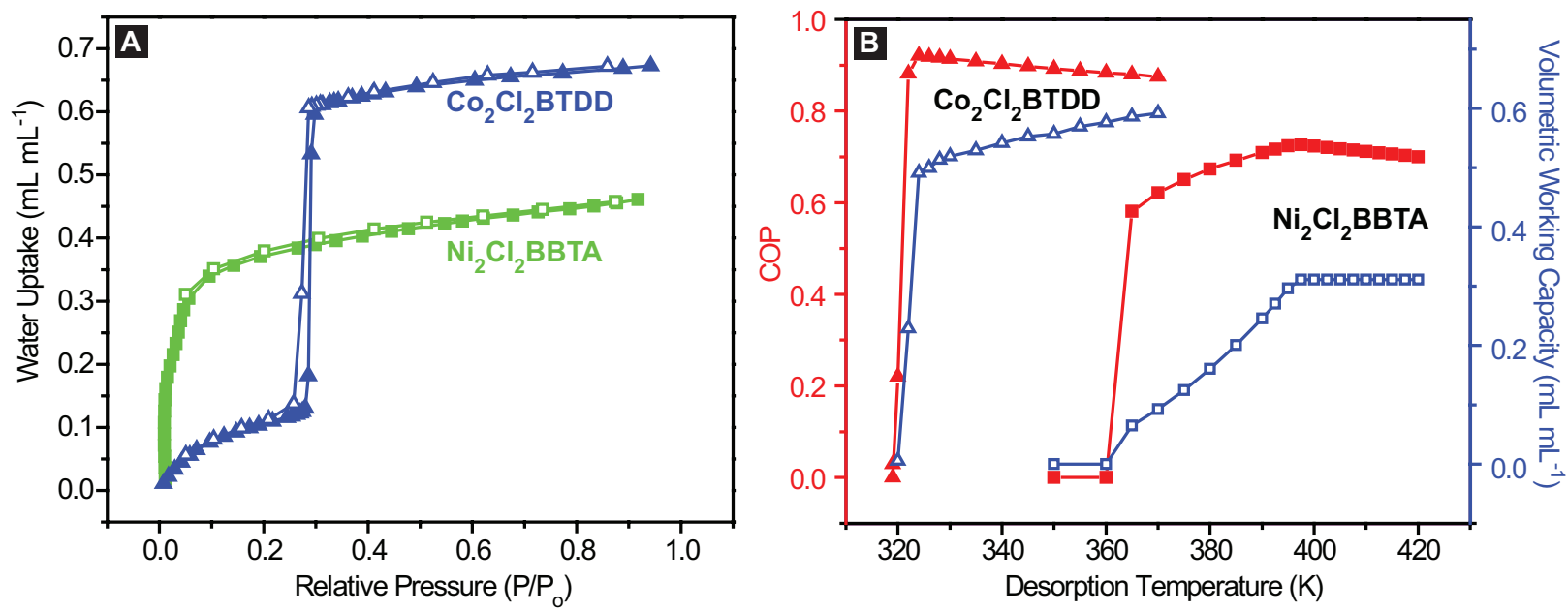

Figure 5: Two-stage cascaded heat pump figures of merit.

A) Water vapor adsorption (filled symbols) and desorption (open symbols) in volumetric units at $298 \mathrm{~K}$ for $\mathrm{Co}_{2} \mathrm{Cl}_{2} \mathrm{BTDD}$ (blue triangles) and $\mathrm{Ni}_{2} \mathrm{Cl}_{2} \mathrm{BBTA}$ (green squares) B) Coefficient of Performance (open symbols, left axis) and volumetric working capacity (filled symbols, right axis) for $\mathrm{Co}_{2} \mathrm{Cl}_{2} \mathrm{BTDD}$ (blue triangles) and $\mathrm{Ni}_{2} \mathrm{Cl}_{2} \mathrm{BBTA}$ (green squares) using an evaporator temperature of $283 \mathrm{~K}$ and an ambient temperature of $300 \mathrm{~K}$, with a minimum bed temperature during adsorption of $330 \mathrm{~K}$ for $\mathrm{Ni}_{2} \mathrm{Cl}_{2} \mathrm{BBTA}$, as a function of desorption temperature.

vapor, for instance the larger-pore $\mathrm{Co}_{2} \mathrm{Cl}_{2} \mathrm{BTDD}$, the sensible heat $\left(\boldsymbol{Q}_{1}\right)$ as well as the energy from $\Delta H_{\text {ads }}\left(\boldsymbol{Q}_{2}\right)$ in the small-pore $\mathrm{Ni}_{2} \mathrm{Cl}_{2} \mathrm{BBTA}$ (Bed 1) at elevated temperature can be used to completely regenerate the larger-pore $\mathrm{Co}_{2} \mathrm{Cl}_{2} \mathrm{BTDD}$ (Bed 2). Both adsorbent beds can be paired with the same evaporator and condenser, at temperatures of $10{ }^{\circ} \mathrm{C}$ and $27{ }^{\circ} \mathrm{C}$ respectively $\left(17{ }^{\circ} \mathrm{C}\right.$ lift). The minimum adsorption temperature of Bed 2 $\left(\mathrm{Co}_{2} \mathrm{Cl}_{2} \mathrm{BTDD}\right)$ would be that of the condenser, $27{ }^{\circ} \mathrm{C}$, and it would be regenerated at 57 ${ }^{\circ} \mathrm{C}$ with waste heat from Bed $1\left(\mathrm{Ni}_{2} \mathrm{Cl}_{2} \mathrm{BBTA}\right)$. In turn, Bed 1 would operate at a minimum adsorption temperature of $57^{\circ} \mathrm{C}$ and be regenerated by an external heat source at $127^{\circ} \mathrm{C}$. This configuration is ideal for the application of district air conditioning for buildings (Figure 4A).

Altogether, $\mathrm{Ni}_{2} \mathrm{Cl}_{2} \mathrm{BBTA}$ and $\mathrm{Co}_{2} \mathrm{Cl}_{2} \mathrm{BTDD}$ combine for a cascaded double-effect AHP cycle in which the input thermal energy for regeneration is effectively used twice, once at $127{ }^{\circ} \mathrm{C}$ to regenerate the small pore $\mathrm{MOF}$, and again at $57^{\circ} \mathrm{C}$ to regenerate the large-pore MOF. In this tandem configuration, $\mathrm{Co}_{2} \mathrm{Cl}_{2} \mathrm{BTDD}$ has a working capacity of $0.52 \mathrm{~mL} \mathrm{~mL}^{-}$ ${ }^{1}$ and a COP of 0.91 when regenerated at $57{ }^{\circ} \mathrm{C}$, whereas $\mathrm{Ni}_{2} \mathrm{Cl}_{2} \mathrm{BBTA}$ has a working capacity of $0.31 \mathrm{~mL} \mathrm{~mL}^{-1}$ and a $\mathrm{COP}$ of 0.72 when regenerated at $127{ }^{\circ} \mathrm{C}$ (Figure 5B). Because the COP of the cascading pump is the sum of the COPs for the constituent cycles, the ideal system COP for the combination presented here is 1.63 .

The thermodynamic cycle is diagrammed in process flow in Figure $4 \mathrm{~A}$ and in a tandem isosteric cycle in Figure 4B. Beginning with a saturated bed of $\mathrm{Ni}_{2} \mathrm{Cl}_{2} \mathrm{BBTA}$ (Bed 1, point $A 1$ ) and an empty bed of $\mathrm{Co}_{2} \mathrm{Cl}_{2} \mathrm{BTDD}$ (Bed 2, point $C 2$ ), Bed 1 undergoes isosteric heating to point $B I$ and its vapor pressure increases from $9.5 \mathrm{mmHg}$ (the pressure of the evaporator) to $26.6 \mathrm{mmHg}$ (the pressure of the condenser). At the same time, Bed 2 undergoes isosteric cooling from point $C 2$ to point $D 2$. Subsequently, Bed 1 is further heated while connected to the condenser for isobaric desorption to point $C 1$, while Bed 2 is connected to the evaporator and undergoes isobaric adsorption to point $A 2$. At this point the roles of the beds 
reverse in the second half-cycle (Figure 4A). Bed 1 is cooled isosterically to point $D 1$, connected to the evaporator, and undergoes isobaric adsorption back to $A 1$ while the sensible heat $\boldsymbol{Q}_{1}$ and the heat of adsorption $\boldsymbol{Q}_{2}$ from this process are used to regenerate Bed 2, moving from $A 2$ to $B 2$ and finally $C 2$ (Figure 4B).

\section{Discussion}

The foregoing results are the first example of materials with thermodynamically-tuned, steep, and non-overlapping water isotherms (Figure 5A) employed in a cascaded adsorption cycle, which enables significantly greater thermal efficiency by reducing the required temperature swings and minimizing the dead thermal mass. For example, using conventional sorbents, which, due to overlapping isotherms neccesitate employing different refigerants for each stage, an AHP with a cooling COP of 1 requires a three-stage cascade with a source temperature of $220{ }^{\circ} \mathrm{C}$.[14] Additionally, previous screening of sorbentsorbate pairs for tandem heat pumps found theoretical maxima for COP of 1.15 for a tandem activated carbon-methanol and zeolite-water cycle.[13] By contrast, using MOFs with stepped water isotherms tuned by pore size, we demonstrate a record ideal COP of 1.63, over $150 \%$ higher than the previous best, notably decreasing complexity by using water as the sole refrigerant, and employing a much lower source temperature of $127^{\circ} \mathrm{C}$.

Triazolate MOFs are uniquely suited to water vapor isotherm engineering by virtue of their exceptional stability as well as their hydrophilic chains of metals exhibiting open coordination sites. The microporous BBTA MOFs adsorb water vapor near $0 \% \mathrm{RH}$. This unusually high hydrophilicity engenders a high driving force for heat transfer. Compared to other materials capable of generating a $25^{\circ} \mathrm{C}$ lift, $\mathrm{Ni}_{2} \mathrm{Cl}_{2} \mathrm{BBTA}$ has the greatest uptake capacity and positions it as a key material for the hot adsorption bed of a cascaded adsorption heat pump. When used in tandem, $\mathrm{Ni}_{2} \mathrm{Cl}_{2} \mathrm{BBTA}$ and $\mathrm{Co}_{2} \mathrm{Cl}_{2} \mathrm{BTDD}$ combine for an unprecedented $\mathrm{COP}$ of 1.63 , which can be achieved using an accessible low driving temperature of only $127^{\circ} \mathrm{C}$. The ability to provide continuous cooling with simultaneously high COP and low source temperatures is a significant advance over the state-of-the-art. This work moves sustainable adsorption heat pumps using water as a refrigerant closer to widespread adoption.

\section{Experimental Procedures}

Water vapor adsorption isotherms were measured by a volumetric method using a Micromeritics ASAP 2020 gas sorption analyzer with a vapor dose option and a heated manifold. A typical sample of ca. $40 \mathrm{mg}$ of metal-organic framework, pre-activated at $100^{\circ} \mathrm{C}$ to remove all residual solvent, was transferred in an Ar filled glovebox to a pre-weighed analysis tube. The tube with sample inside was weighed again to determine the mass of the sample. The tube was capped with a Micromeritics TranSeal, brought out of the glovebox, and transferred to the analysis port of the gas sorption analyzer. Free space correction measurements were performed using ultra-high purity He gas (UHP grade 5, 99.999\% pure). Water vapor adsorption isotherms were measured using Milli-Q water. The water was degassed on the ASAP 2020 manifold prior to measurement. All analyses were performed using a water bath held at constant temperature with a recirculating chiller. The manifold was held $15^{\circ} \mathrm{C}$ above the temperature of the sample water bath, and the vapor dosing tube was held $10^{\circ} \mathrm{C}$ above the temperature of the sample water bath. Oil-free vacuum pumps were used to prevent contamination of sample or feed gases. 


\section{Acknowledgements}

AJR is supported by the MIT Tata Center for Technology and Design. We thank the Abdul Latif Jameel World Water and Food Security Lab for Seed funding for water capture.

\section{Author Contributions}

AJR and MD conceived of experiments. AJR and AMW synthesized materials and performed experiments. AJR, SR, HK, and ENW designed and calculated parameters for the cascaded thermal cycle. ADL performed cycling experiments. AJR wrote the initial manuscript. AJR, AMW, SR, $\mathrm{HK}, \mathrm{ADL}, \mathrm{ENW}$, and MD revised the manuscript.

\section{Declaration of Interests}

AJR and MD are inventors on a patent pertaining to the materials discussed herein.

\section{References}

[1] U.S. Energy Information Agency. Annual Energy Outlook 2015 with Projections to 2040. Washington, DC: 2015.

[2] Reese A. Slow coolant phaseout could worsen warming: As countries crank up the AC, emissions of potent greenhouse gases are likely to skyrocket. Science 2018;359:1084. doi:10.1126/science.359.6380.1084.

[3] Critoph RE. Evaluation of alternative refrigerant-adsorbent pairs for refrigeration cycles. Appl Therm Eng 1996;16:891-900. doi:10.1016/1359-4311(96)00008-7.

[4] Jeremias F, Fröhlich D, Janiak C, Henninger SK. Advancement of sorption-based heat transformation by a metal coating of highly-stable, hydrophilic aluminium fumarate MOF. RSC Adv 2014;4:24073. doi:10.1039/c4ra03794d.

[5] Narayanan S, Yang S, Kim H, Wang EN. Optimization of adsorption processes for climate control and thermal energy storage. Int J Heat Mass Transf 2014;77:288-300. doi:10.1016/j.ijheatmasstransfer.2014.05.022.

[6] Greenblatt JB, Wei M. Assessment of the climate commitments and additional mitigation policies of the United States. Nat Clim Chang 2016;6:1090-3.

[7] Anderson JB, Catania G a, Alley RB, Anandakrishnan S, Dupont TK, Pollard D, et al. CO2 Is Not the Only Gas. Science 2007;315:1804-5.

[8] McLinden MO, Brown JS, Brignoli R, Kazakov AF, Domanski PA. Limited options for low-global-warming-potential refrigerants. Nat Commun 2017;8:1-9. doi:10.1038/ncomms14476.

[9] De Lange MF, Verouden KJFM, Vlugt TJH, Gascon J, Kapteijn F. Adsorption-Driven Heat Pumps: The Potential of Metal-Organic Frameworks. Chem Rev 2015;115:1220550. doi:10.1021/acs.chemrev.5b00059.

[10] Ehrenmann J, Henninger SK, Janiak C. Water Adsorption Characteristics of MIL-101 for Heat-Transformation Applications of MOFs. Eur J Inorg Chem 2011;2011:471-4. doi:10.1002/ejic.201001156.

[11] Canivet J, Bonnefoy J, Daniel C, Legrand A, Coasne B, Farrusseng D. Structure-property relationships of water adsorption in metal-organic frameworks. New J Chem 2014;38:3102. doi:10.1039/c4nj00076e.

[12] Küsgens P, Rose M, Senkovska I, Fröde H, Henschel A, Siegle S, et al. Characterization of metal-organic frameworks by water adsorption. Microporous Mesoporous Mater 
2009;120:325-30. doi:10.1016/j.micromeso.2008.11.020.

[13] Meunier F. Theoretical Performances of Solid Adsorbent Cascading Cycles Using the Zeolite-Water and Active Carbon-Methanol Pairs: Four Case Studies. J Heat Recover Syst 1986;6:491-8.

[14] Douss N, Meunier F. Experimental study of cascading adsorption cycles. Chem Eng Sci 1989;44:225-35. doi:10.1016/0009-2509(89)85060-2.

[15] Cadiau A, Lee JS, Damasceno Borges D, Fabry P, Devic T, Wharmby MT, et al. Design of Hydrophilic Metal Organic Framework Water Adsorbents for Heat Reallocation. Adv Mater 2015;27:4775-80. doi:10.1002/adma.201502418.

[16] Rieth AJ, Yang S, Wang EN, Dincă M. Record Atmospheric Fresh Water Capture and Heat Transfer with a Material Operating at the Water Uptake Reversibility Limit. ACS Cent Sci 2017;3:668-72. doi:10.1021/acscentsci.7b00186.

[17] Jeremias F, Khutia A, Henninger SK, Janiak C. MIL-100(Al, Fe) as water adsorbents for heat transformation purposes - a promising application. J Mater Chem 2012;22:10148. doi:10.1039/c2jm15615f.

[18] Wade CR, Corrales-Sanchez T, Narayan TC, Dincă M. Postsynthetic tuning of hydrophilicity in pyrazolate MOFs to modulate water adsorption properties. Energy Environ Sci 2013;6:2172. doi:10.1039/c3ee40876k.

[19] Wright AM, Rieth AJ, Yang S, Wang E, Dinca M. Precise control of pore hydrophilicity enabled by post-synthetic cation exchange in metal-organic frameworks. Chem Sci 2018;9:3856. doi:10.1039/C8SC00112J.

[20] Akiyama G, Matsuda R, Sato H, Hori A, Takata M, Kitagawa S. Effect of functional groups in MIL-101 on water sorption behavior. Microporous Mesoporous Mater 2012;157:89-93. doi:10.1016/j.micromeso.2012.01.015.

[21] Jeremias F, Lozan V, Henninger SK, Janiak C. Programming MOFs for water sorption: amino-functionalized MIL-125 and UiO-66 for heat transformation and heat storage applications. Dalton Trans 2013;42:15967-73. doi:10.1039/c3dt51471d.

[22] Canivet J, Fateeva A, Guo Y, Coasne B, Farrusseng D. Water adsorption in MOFs: fundamentals and applications. Chem Soc Rev 2014;43:5594-617. doi:10.1039/c4cs00078a.

[23] Coasne B, Gubbins KE, Pellenq RJM. Temperature effect on adsorption/desorption isotherms for a simple fluid confined within various nanopores. Adsorption 2005;11:28994. doi:10.1007/s10450-005-5939-y.

[24] Jasuja H, Zang J, Sholl DS, Walton KS. Rational tuning of water vapor and CO 2 adsorption in highly stable Zr-based MOFs. J Phys Chem C 2012;116:23526-32. doi:10.1021/jp308657x.

[25] Burtch NC, Jasuja H, Walton KS. Water Stability and Adsorption in Metal - Organic Frameworks. Chem Rev 2014;114:10575-612. doi:10.1021/cr5002589.

[26] Rieth AJ, Tulchinsky Y, Dincă M. High and Reversible Ammonia Uptake in Mesoporous Azolate Metal-Organic Frameworks with Open Mn, Co, and Ni Sites. J Am Chem Soc 2016;138:9401-4. doi:10.1021/jacs.6b05723.

[27] Liao P-Q, Li X-Y, Bai J, He C-T, Zhou D-D, Zhang W-X, et al. Drastic enhancement of catalytic activity via post-oxidation of a porous MnII triazolate framework. Chem - A Eur J 2014;20:11303-7. doi:10.1002/chem.201403123.

[28] Liao P-Q, Chen H, Zhou D-D, Liu S-Y, He C-T, Rui Z, et al. Monodentate hydroxide as a super strong yet reversible active site for $\mathrm{CO}_{2}$ capture from high-humidity flue gas. 
Energy Environ Sci 2015;8:1011-6. doi:10.1039/C4EE02717E.

[29] Rieth AJ, Dincă M. Controlled Gas Uptake in Metal-Organic Frameworks with Record Ammonia Sorption. J Am Chem Soc 2018;140:3461-6. doi:10.1021/jacs.8b00313.

[30] Derouane EG, Chang CD. Confinement effects in the adsorption of simple bases by zeolites. Microporous Mesoporous Mater 2000;35-36:425-33. doi:10.1016/S13871811(99)00239-5.

[31] de Lange MF, van Velzen BL, Ottevanger CP, Verouden KJFM, Lin L-C, Vlugt TJH, et al. Metal-Organic Frameworks in Adsorption-Driven Heat Pumps: The Potential of Alcohols as Working Fluids. Langmuir 2015;31:12783-96. doi:10.1021/acs.langmuir.5b03272.

[32] Carter JW, Wyszynski ML. The pressure swing adsorption drying of compressed air. Chem Eng Sci 1983;38:1093-9. doi:10.1016/0009-2509(83)80030-X. 


\section{Supplemental Information}

\section{Tunable Metal-Organic Frameworks Enable High Efficiency Cascaded Adsorption Heat Pumps}

Adam J. Rieth ${ }^{1}$, Ashley M. Wright ${ }^{1}$, Sameer Rao ${ }^{2}$, Hyunho Kim² ${ }^{2}$, Alina D. LaPotin ${ }^{2}$, Evelyn N. Wang ${ }^{2}$, and Mircea Dincă ${ }^{1 *}$

${ }^{1}$ Department of Chemistry, Massachusetts Institute of Technology, 77 Mass. Ave. Cambridge, Massachusetts, 02139, United States.

${ }^{2}$ Department of Mechanical Engineering, Massachusetts Institute of Technology, 77 Mass. Ave. Cambridge, Massachusetts, 02139, United States.

*Corresponding Author: mdinca@mit.edu

Table of Contents

Materials and Methods.

Calculations of Characteristic Curve, Temperature Lift, COP

Figures S1 - S11.

References
Page

S2

S3-S4

S5-S15

S16 


\section{Materials and Methods}

$\mathrm{CuCl}_{2} \bullet 4 \mathrm{H}_{2} \mathrm{O}\left(98 \%\right.$, Strem Chemicals), $\mathrm{CoCl}_{2} \bullet 6 \mathrm{H}_{2} \mathrm{O}$ (99.9\%, Alfa Aesar), $\mathrm{NiCl}_{2} \bullet 6 \mathrm{H}_{2} \mathrm{O}$ (Strem Chemicals), $\mathrm{HCl}(32-35 \%, \mathrm{BDH}-\mathrm{VWR}$ Analytic) methanol (99.9\%, VWR), $N, N-$ dimethylformamide (99.8\%, Millipore), ethanol (ACS grade, Mallinckrodt) were used as received.

Powder X-ray diffraction (PXRD) patterns were recorded with a Bruker Advance II diffractometer equipped with a $\theta / 2 \theta$ Bragg-Brentano geometry and Ni-filtered $\mathrm{CuK} \alpha$ radiation $\left(\mathrm{K} \alpha_{1}=1.5406 \AA, \mathrm{K} \alpha_{2}=1.5444 \AA, \mathrm{K} \alpha_{1} / \mathrm{K} \alpha_{2}=0.5\right)$. The tube voltage and current were $40 \mathrm{kV}$ and $40 \mathrm{~mA}$, respectively. Samples for PXRD were prepared by placing a thin layer of the appropriate material on a zero-background silicon crystal plate.

Nitrogen adsorption isotherms were measured by a volumetric method using a Micromeritics ASAP 2020 gas sorption analyzer. A typical sample of ca. $40 \mathrm{mg}$ of metal-organic framework, pre-activated at $100^{\circ} \mathrm{C}$ to remove all residual solvent, was transferred in an Ar filled glovebox to a pre-weighed analysis tube. The tube with sample inside was weighed again to determine the mass of the sample. The tube was capped with a Micromeritics TranSeal, brought out of the glovebox, and transferred to the analysis port of the gas sorption analyzer. Free space correction measurements were performed using ultra-high purity He gas (UHP grade 5, 99.999\% pure). Nitrogen isotherms were measured using UHP grade nitrogen. All nitrogen analyses were performed using a liquid nitrogen bath at $77 \mathrm{~K}$. Oil-free vacuum pumps were used to prevent contamination of sample or feed gases.

Water vapor adsorption cycling experiments were performed using a Surface Measurement Systems DVS Adventure dynamic gravimetric water sorption analyzer. A typical sample of ca. 5 $\mathrm{mg}$ of MOF, pre-activated at $150{ }^{\circ} \mathrm{C}$, but later exposed to air, was loaded into the microbalance. The instrument was set to deliver a constant vapor pressure of $4.76 \mathrm{mmHg}$. The baseline mass of the sample was measured over 2 hours at the desorption temperature. The sample was then cycled between the adsorption temperature, and the desorption temperature 10 times. The sample mass was measured once per minute. Heating and cooling ramp rates were $1{ }^{\circ} \mathrm{C}$ per minute. The instrument switched to the next cycle when the change in mass per minute was less than $0.02 \%$.

$\mathrm{M}_{2} \mathrm{Cl}_{2} \mathrm{BBTA}$ MOFs were synthesized and activated according to previously published procedures.[1-3] 
Calculation of the Characteristic Curve for $\mathrm{Ni}_{2} \mathrm{Cl}_{2}$ BBTA.

In order to make the loading dependent on only one free variable (A, energy) rather than two $(P, T)$, we constructed a characteristic curve.[4-6] The energy parameter used is the adsorption potential $(A)$, which is the Gibbs free energy of adsorption with inverse sign:

$$
A=R T \ln \left(\frac{p_{o}(T)}{p}\right)
$$

$p_{o}$ is the saturation vapor pressure of the working fluid at the temperature of analysis, $p$ is the pressure at each loading value, $\mathrm{R}$ is the ideal gas constant, and $\mathrm{T}$ is the analysis temperature.

Isotherms measured at different temperatures should collapse onto a single characteristic curve. Water isotherms for $\mathrm{Ni}_{2} \mathrm{Cl}_{2} \mathrm{BBTA}$ were measured at $283 \mathrm{~K}, 288 \mathrm{~K}$, and $296 \mathrm{~K}$ (Figure S7). After calculating the characteristic curve using each of these isotherms, it is evident that they all collapse into a single characteristic curve (Figure S9) confirming the validity of the characteristic curve model.

The characteristic curve for the highest temperature $296 \mathrm{~K}$ isotherm, that closest to the temperatures typically found in AHP systems, was then fitted with a simple cubic equation in order to easily extrapolate the water loading for any A value (Figure S10)

Calculation of the Heat Transferred per cycle as a Function of Temperature Lift for the Water$\mathrm{Ni}_{2} \mathrm{Cl}_{2}$ BBTA working pair (Figure $3 \mathrm{~B}$ ).

To determine temperature lift, the evaporator temperature, which determines the vapor pressure of the water being adsorbed by the MOF, was varied while the condenser at ambient temperature (set equal to the minimum temperature of the MOF bed) was held constant at 303 $\mathrm{K}$ or $313 \mathrm{~K}$ and the desorption temperature was held constant at $405 \mathrm{~K}$ or $415 \mathrm{~K}$. The adsorption potential was then calculated for the empty state, using the vapor pressure and temperature at desorption conditions, that is, the vapor pressure of the condenser, and the desorption temperature. The adsorption potential was also calculated for the full state, using a bed temperature of $303 \mathrm{~K}$ or $313 \mathrm{~K}$ and with the water vapor pressure allowed to vary with the condenser temperature from $273 \mathrm{~K}$ to $303 \mathrm{~K}$ or $313 \mathrm{~K}\left(30^{\circ}\right.$ or $40^{\circ}$ lift). The adsorption potential values were then converted to loadings of water in $\mathrm{Ni}_{2} \mathrm{Cl}_{2} \mathrm{BBTA}$ by using the previously determined cubic equation fitted to the characteristic curve. The desorption loading was then subtracted from the adsorption loading to determine the net working capacity. Loading values of water per gram MOF were then converted into energy values using the enthalpy of evaporation of water $\left(44 \mathrm{~J} \mathrm{~g}^{-1}\right)$. Gravimetric values were converted into volumetric values using the crystal density of the MOF $\left(1.1 \mathrm{~g} \mathrm{~cm}^{-3}\right)$.

Calculation of the Coefficient of Performance for the Water- $\mathrm{Ni}_{2} \mathrm{Cl}_{2}$ BBTA working pair.

The COP for cooling with a $25^{\circ} \mathrm{C}$ temperature lift (Refrigeration II conditions as defined by De Lange, et. al)[6] was calculated as described in the literature.[4,5] Briefly, the COP for cooling is defined as:

$$
\frac{Q_{e v}}{Q_{\text {regen }}}
$$


The COP for single-stage cooling may vary between 0 and 1. $Q_{e v}$ is the heat energy removed from the evaporator through evaporation of the working fluid, and $Q_{r e g e n}$ is the heat energy required to regenerate the adsorbent, including isosteric heating, of both the adsorbent and the working fluid, and isobaric desorption steps. The enthalpy of adsorption of water in $\mathrm{Ni}_{2} \mathrm{Cl}_{2} \mathrm{BBTA}$ was assumed to be $53 \mathrm{~kJ} \mathrm{~mol}^{-1}$ throughout the working range. This is the enthalpy of adsorption at the pore filling step (Figure S8). The heat capacity of the sorbent was assumed constant at $1 \mathrm{~J} \mathrm{~g}^{-1}$ $\mathrm{K}^{-1}$, in accordance with the literature.[6] The relevant temperatures for the calculation for refrigeration II[6] conditions are $\mathrm{T}_{\text {cond }}=303 \mathrm{~K}, \mathrm{~T}_{\mathrm{ev}}=278 \mathrm{~K}$. The desorption temperature was varied. The COP for cooling applications with a $25^{\circ} \mathrm{C}$ or $35^{\circ} \mathrm{C}$ temperature lift for water in $\mathrm{Ni}_{2} \mathrm{Cl}_{2} \mathrm{BBTA}$ at varied desorption temperature is shown in Figure $3 \mathrm{~A}$.

\section{Calculation of the Coefficient of Performance for the Tandem Cycle working pair.}

For the tandem cycle, similar calculations as above were employed for each bed separately. The total COP for the combined tandem cycle is then the sum of the COP for each component bed.

In order to match the thermal energy available from bed 1 of $\mathrm{Ni}_{2} \mathrm{Cl}_{2} \mathrm{BBTA}$ with the required regeneration energy for bed 2 , the bed sizes can be adjusted based on the relative thermal energy required for each material. For instance, moving from $C 1$ to $A 1$ (Figure 4B), $\mathrm{Ni}_{2} \mathrm{Cl}_{2} \mathrm{BBTA}$ dissipates $958 \mathrm{~J} \mathrm{~g}^{-1}$ of thermal energy and for regeneration from $A 2$ to $C 2, \mathrm{Co}_{2} \mathrm{Cl}_{2} \mathrm{BTDD}$ requires $1997 \mathrm{~J} \mathrm{~g}^{-1}$, meaning that 2.08 times as much $\mathrm{Ni}_{2} \mathrm{Cl}_{2} \mathrm{BBTA}$ than $\mathrm{Co}_{2} \mathrm{Cl}_{2} \mathrm{BTDD}$ by mass should be employed. Thus, for a $10 \mathrm{~kg}(14.4 \mathrm{~L})$ bed of $\mathrm{Co}_{2} \mathrm{Cl}_{2} \mathrm{BTDD}$, a $20.8 \mathrm{~kg}(18.9 \mathrm{~L})$ bed of $\mathrm{Ni}_{2} \mathrm{Cl}_{2} \mathrm{BBTA}$ should be used, which will provide continuous cooling with a $17^{\circ} \mathrm{C}$ lift and an ideal $\mathrm{COP}$ of 1.63. Per cycle, $18300 \mathrm{~kJ}$ of thermal energy will be transferred for $\mathrm{Co}_{2} \mathrm{Cl}_{2} \mathrm{BTDD}$ and $14400 \mathrm{~kJ}$ for $\mathrm{Ni}_{2} \mathrm{Cl}_{2} \mathrm{BBTA}$. 


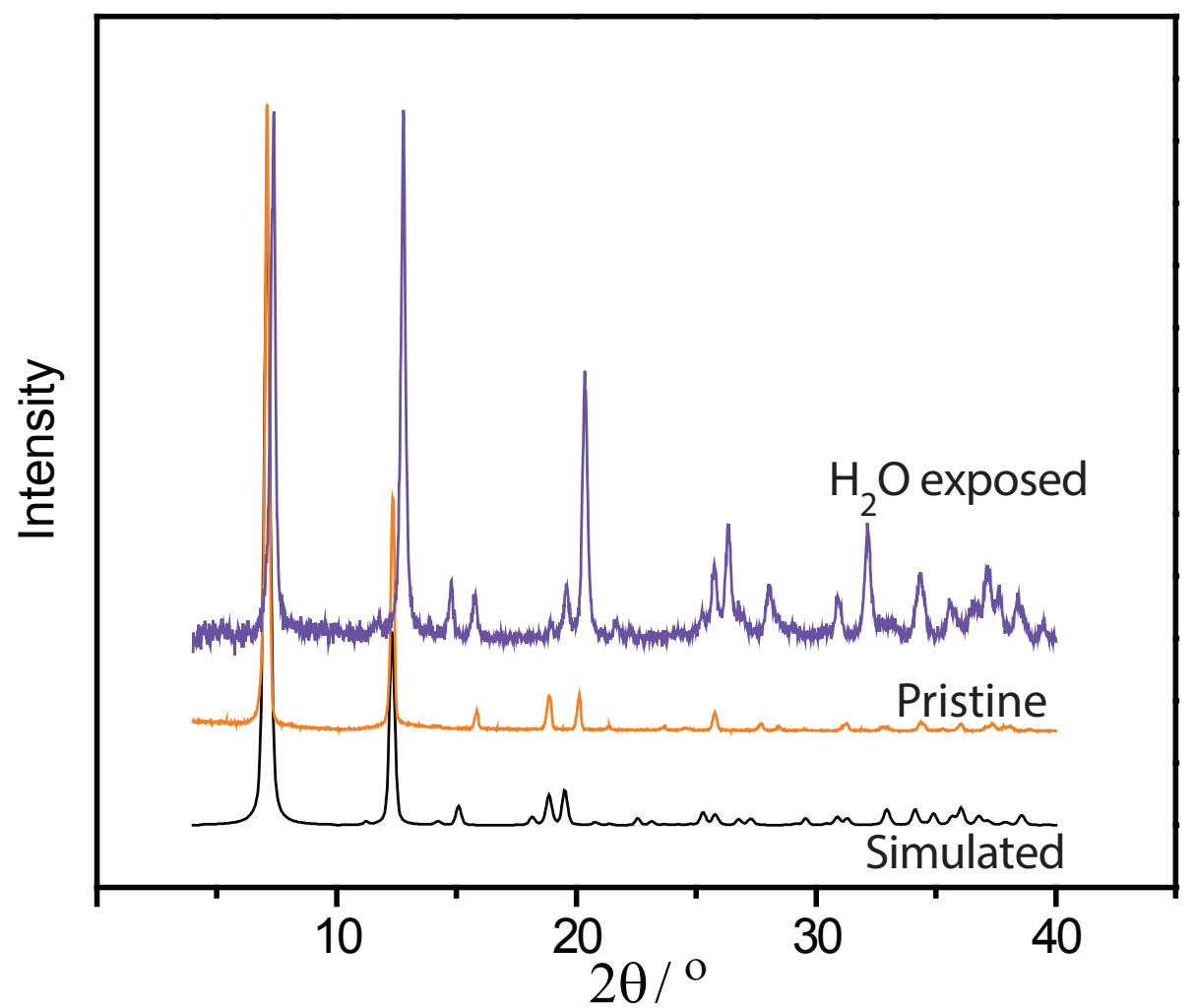

Figure S1. Powder X-ray diffraction patterns of activated $\mathrm{Cu}_{2} \mathrm{Cl}_{2} \mathrm{BBTA}$ (orange), $\mathrm{Cu}_{2} \mathrm{Cl}_{2} \mathrm{BBTA}$ after a single water isotherm at $298 \mathrm{~K}$ (purple), and a simulated pattern for the structure (black). 


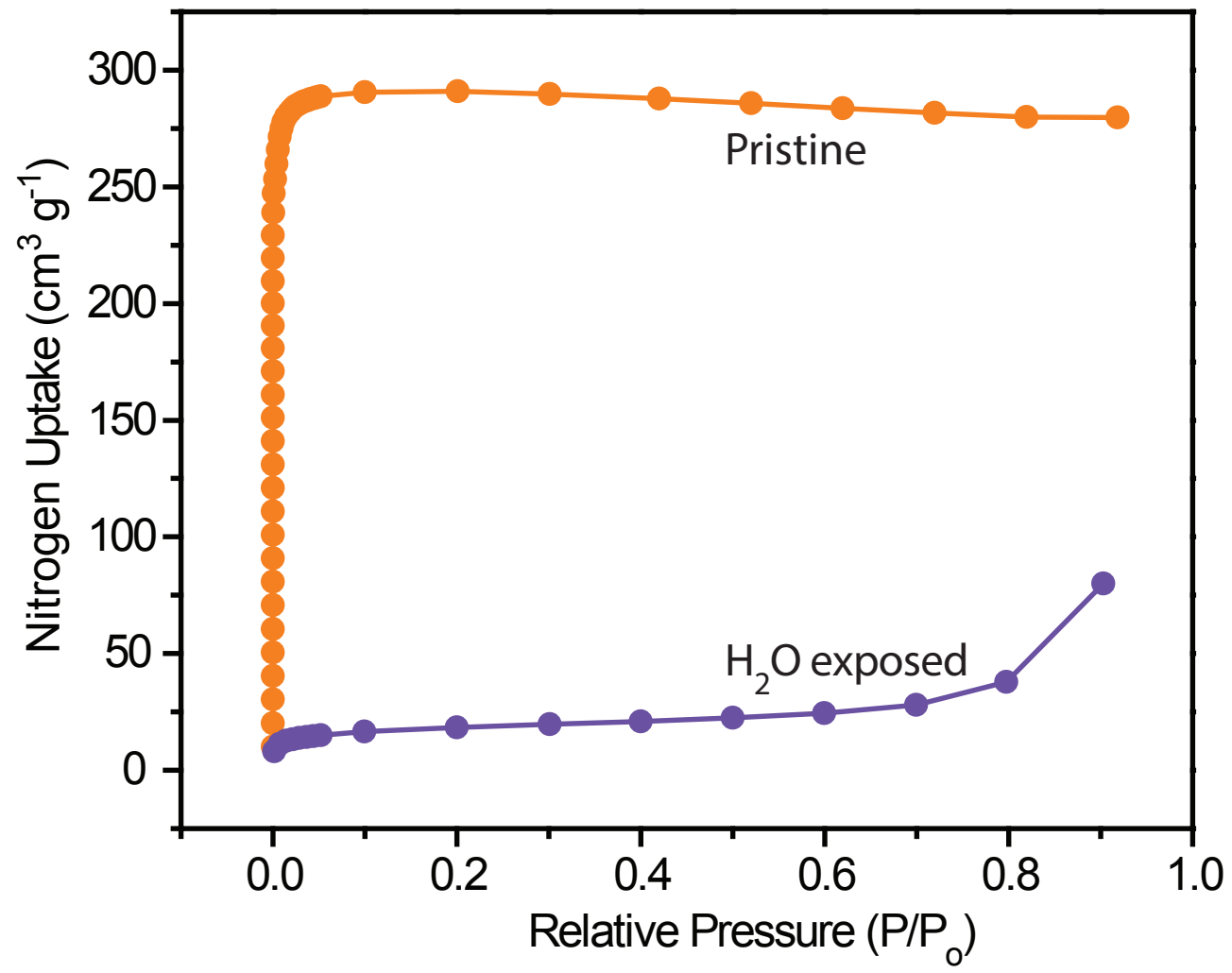

Figure S2. $\mathrm{N}_{2}$ adsorption isotherms of activated $\mathrm{Cu}_{2} \mathrm{Cl}_{2} \mathrm{BBTA}$ (orange), and $\mathrm{Cu}_{2} \mathrm{Cl}_{2} \mathrm{BBTA}$ reactivated at $150^{\circ} \mathrm{C}$ after a single water isotherm at $298 \mathrm{~K}$ (purple). 


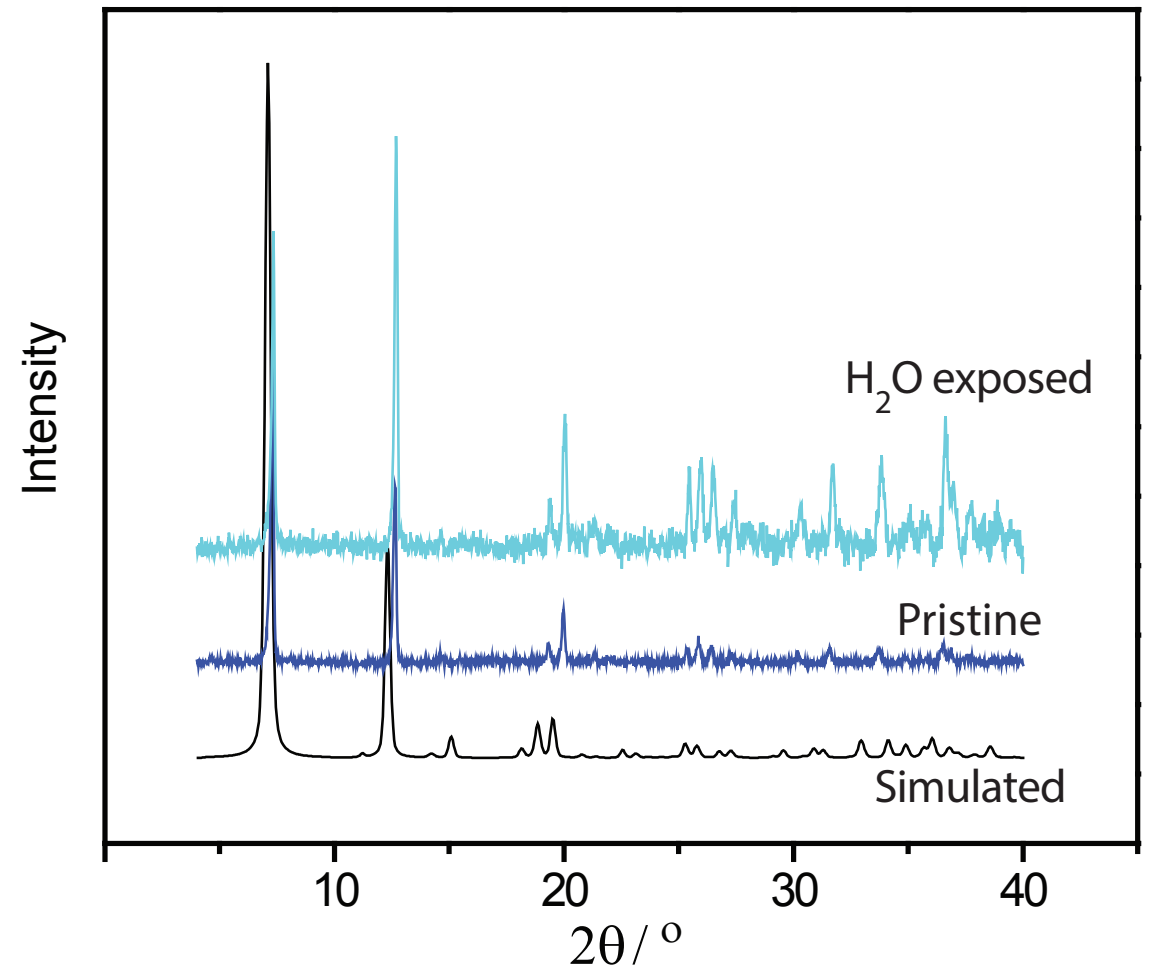

Figure S3. Powder X-ray diffraction patterns of activated $\mathrm{CO}_{2} \mathrm{Cl}_{2} \mathrm{BBTA}$ (blue), $\mathrm{Co}_{2} \mathrm{Cl}_{2} \mathrm{BBTA}$ after a single water isotherm at $298 \mathrm{~K}$ (light blue), and a simulated pattern for the structure (black). 


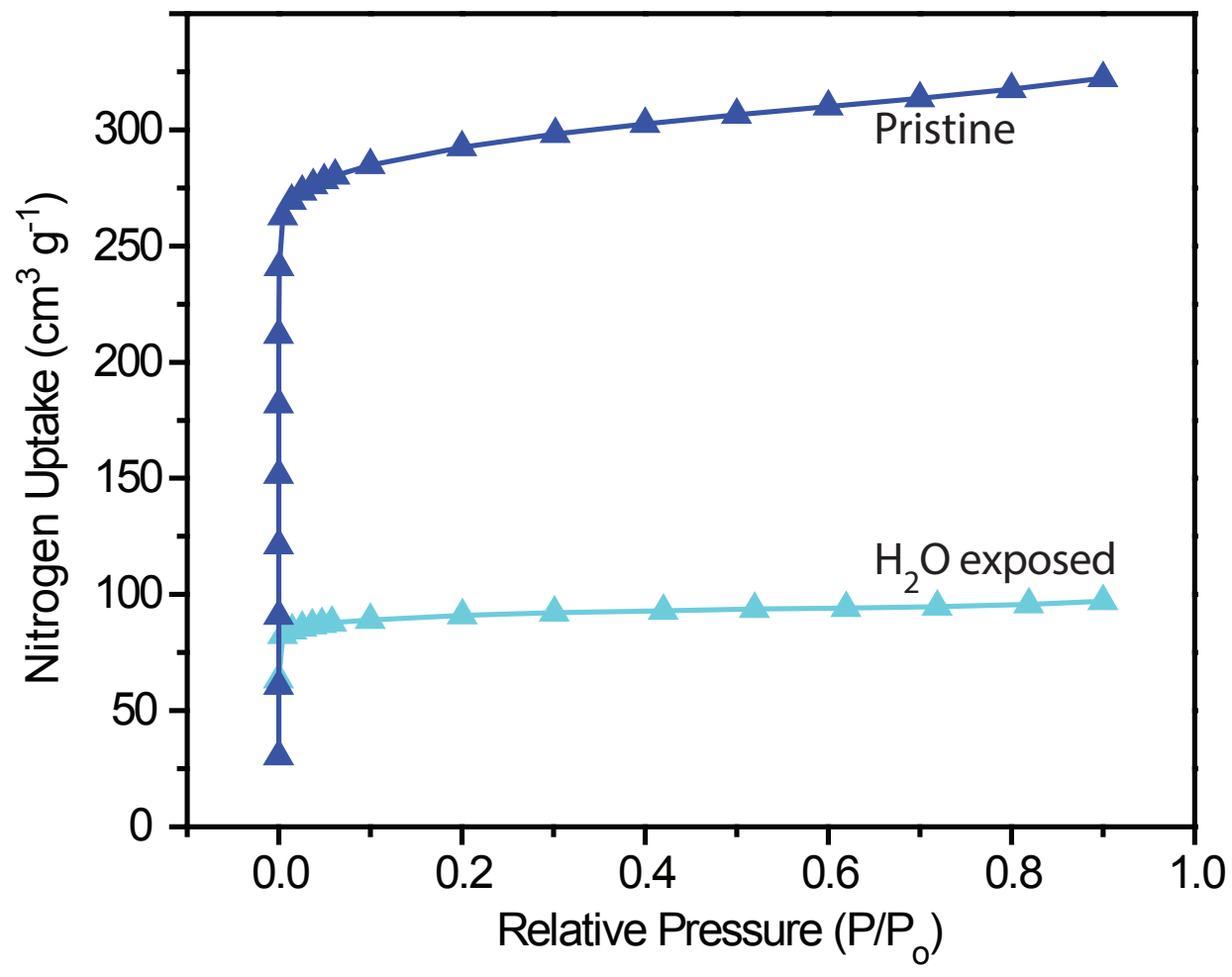

Figure S4. $\mathrm{N}_{2}$ adsorption isotherms of activated $\mathrm{Co}_{2} \mathrm{Cl}_{2} \mathrm{BBTA}$ (blue), and $\mathrm{CO}_{2} \mathrm{Cl}_{2} \mathrm{BBTA}$ reactivated at $150^{\circ} \mathrm{C}$ after a single water isotherm at $298 \mathrm{~K}$ (light blue). 


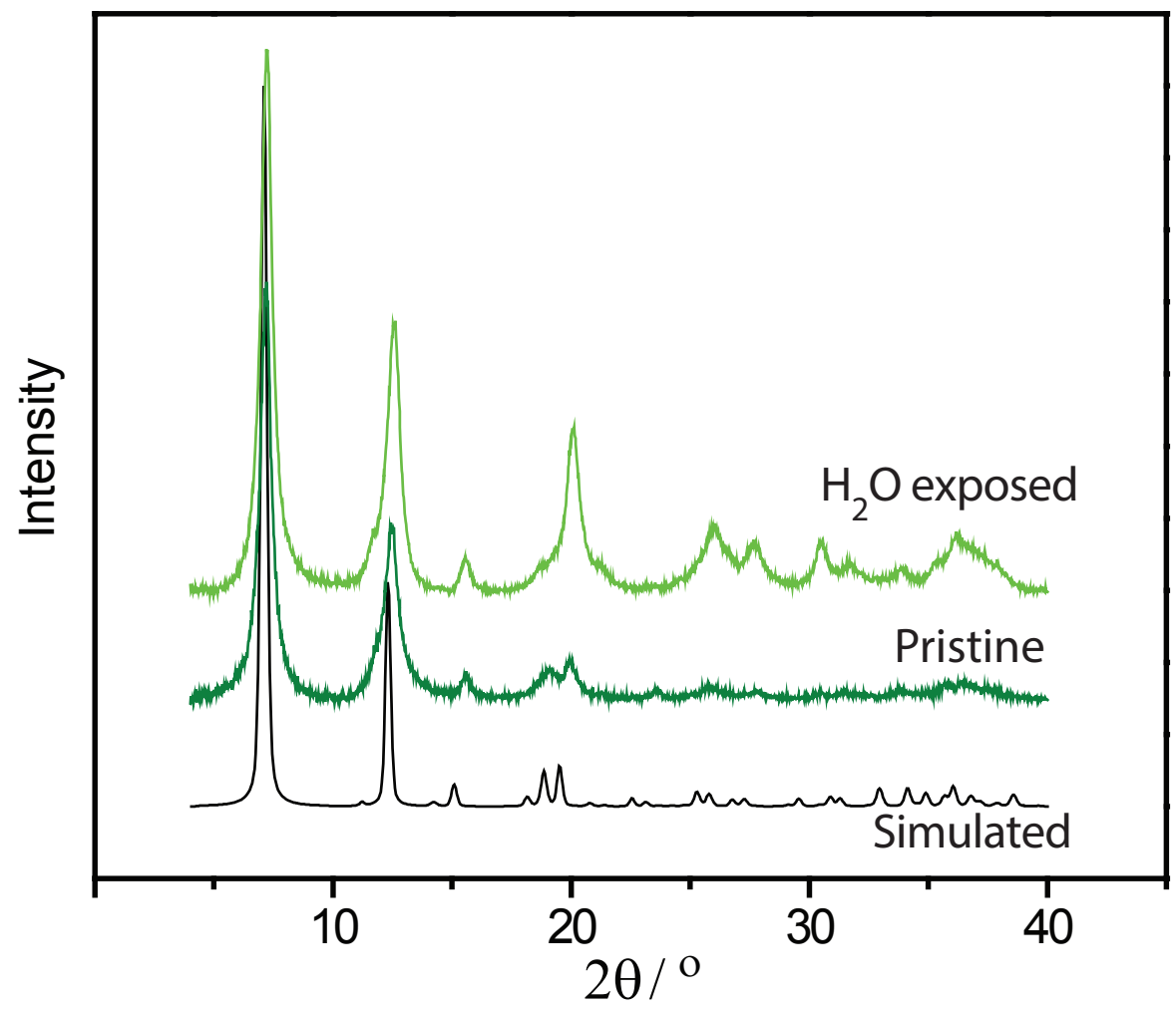

Figure S5. Powder X-ray diffraction patterns of activated $\mathrm{Ni}_{2} \mathrm{Cl}_{2} \mathrm{BBTA}$ (dark green), $\mathrm{Ni}_{2} \mathrm{Cl}_{2} \mathrm{BBTA}$ after a single water isotherm at $296 \mathrm{~K}$ (light green), and a simulated pattern for the structure (black). 


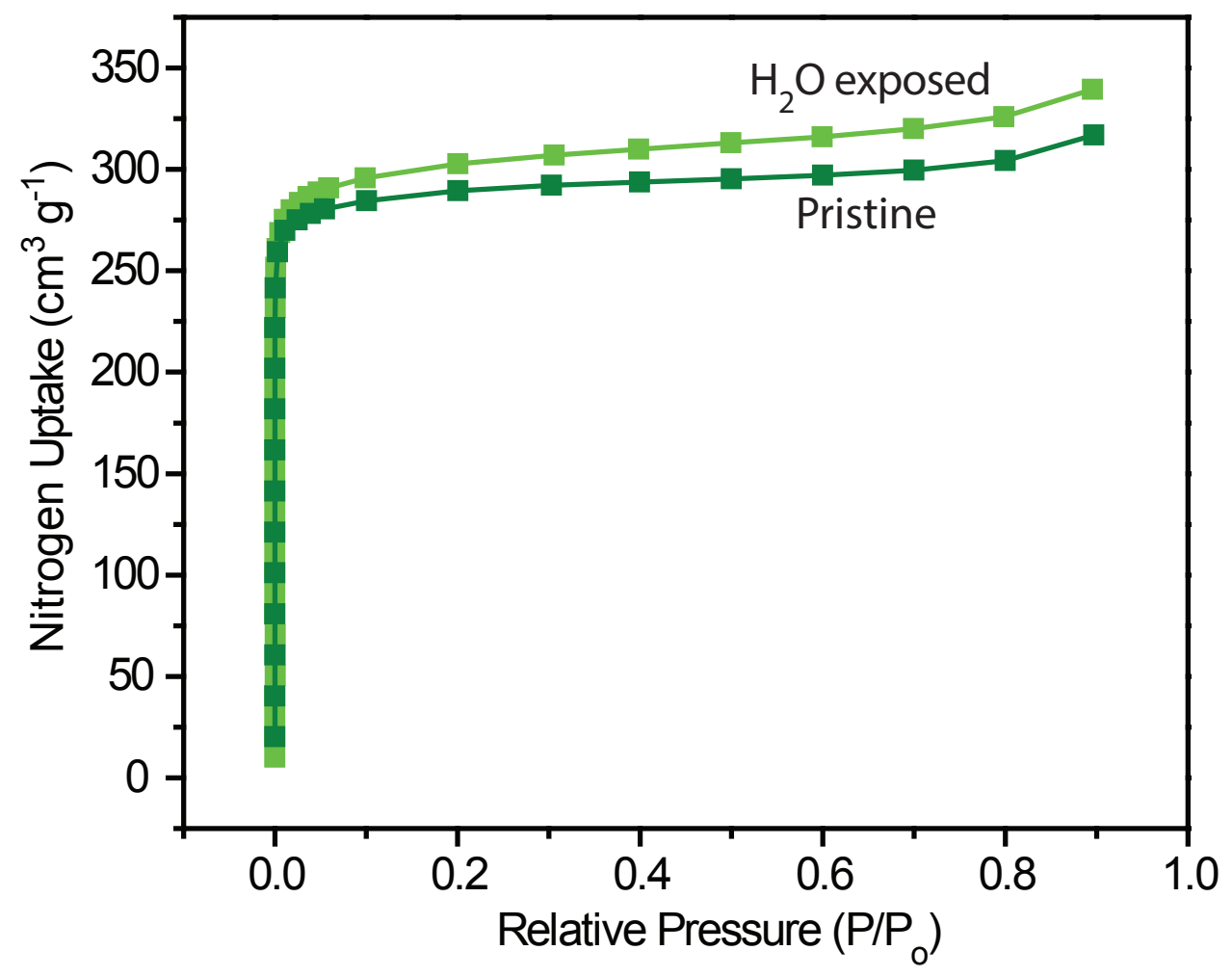

Figure S6. $\mathrm{N}_{2}$ adsorption isotherms of activated $\mathrm{Ni}_{2} \mathrm{Cl}_{2} \mathrm{BBTA}$ (dark green), and $\mathrm{Ni}_{2} \mathrm{Cl}_{2} \mathrm{BBTA}$ reactivated at $150^{\circ} \mathrm{C}$ after a single water isotherm at $296 \mathrm{~K}$ (light green). 


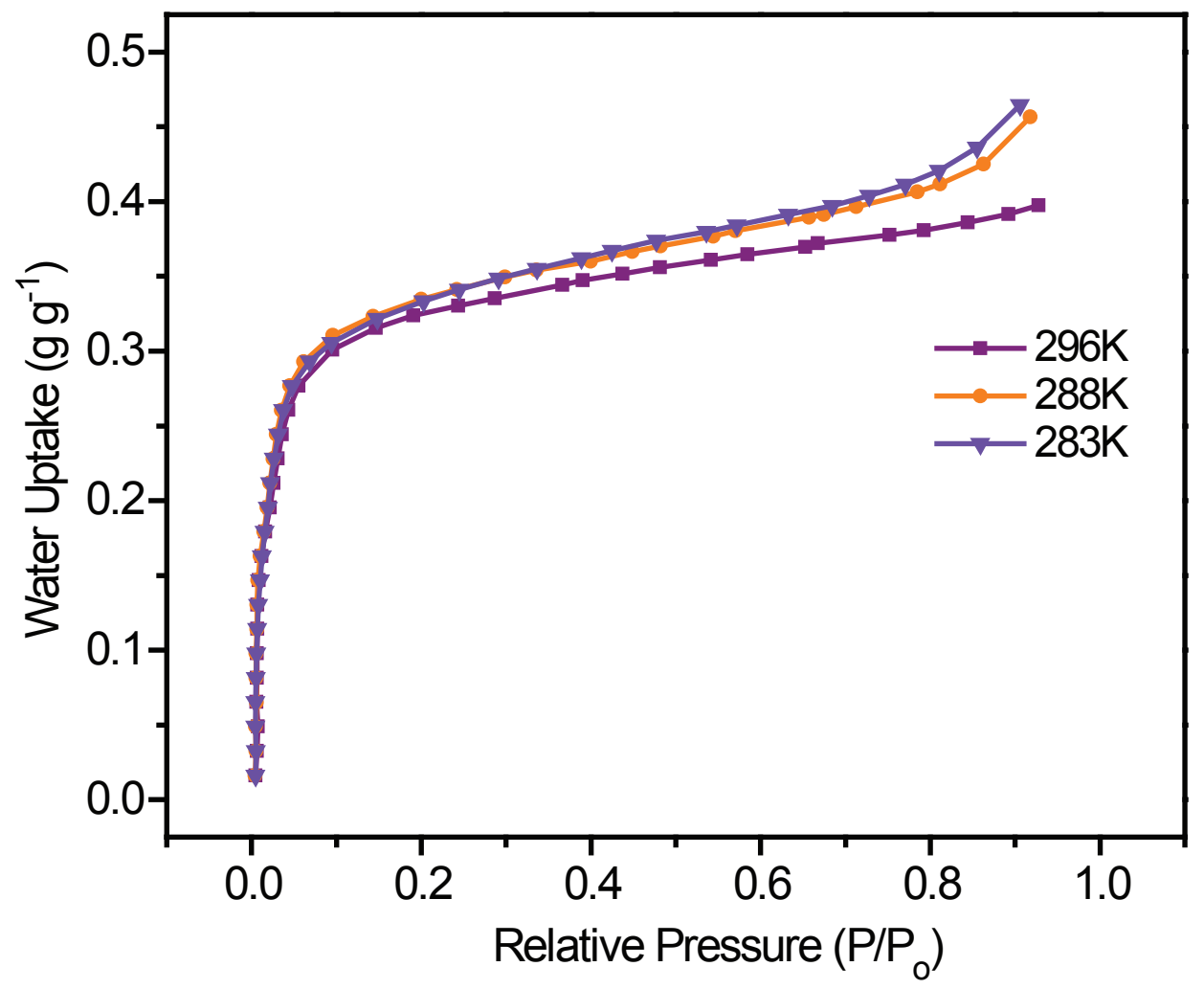

Figure S7. Variable temperature water adsorption isotherms for $\mathrm{Ni}_{2} \mathrm{Cl}_{2} \mathrm{BBTA}$ at $296 \mathrm{~K}$ (purple squares), $288 \mathrm{~K}$ (orange circles), and $283 \mathrm{~K}$ (blue triangles). 


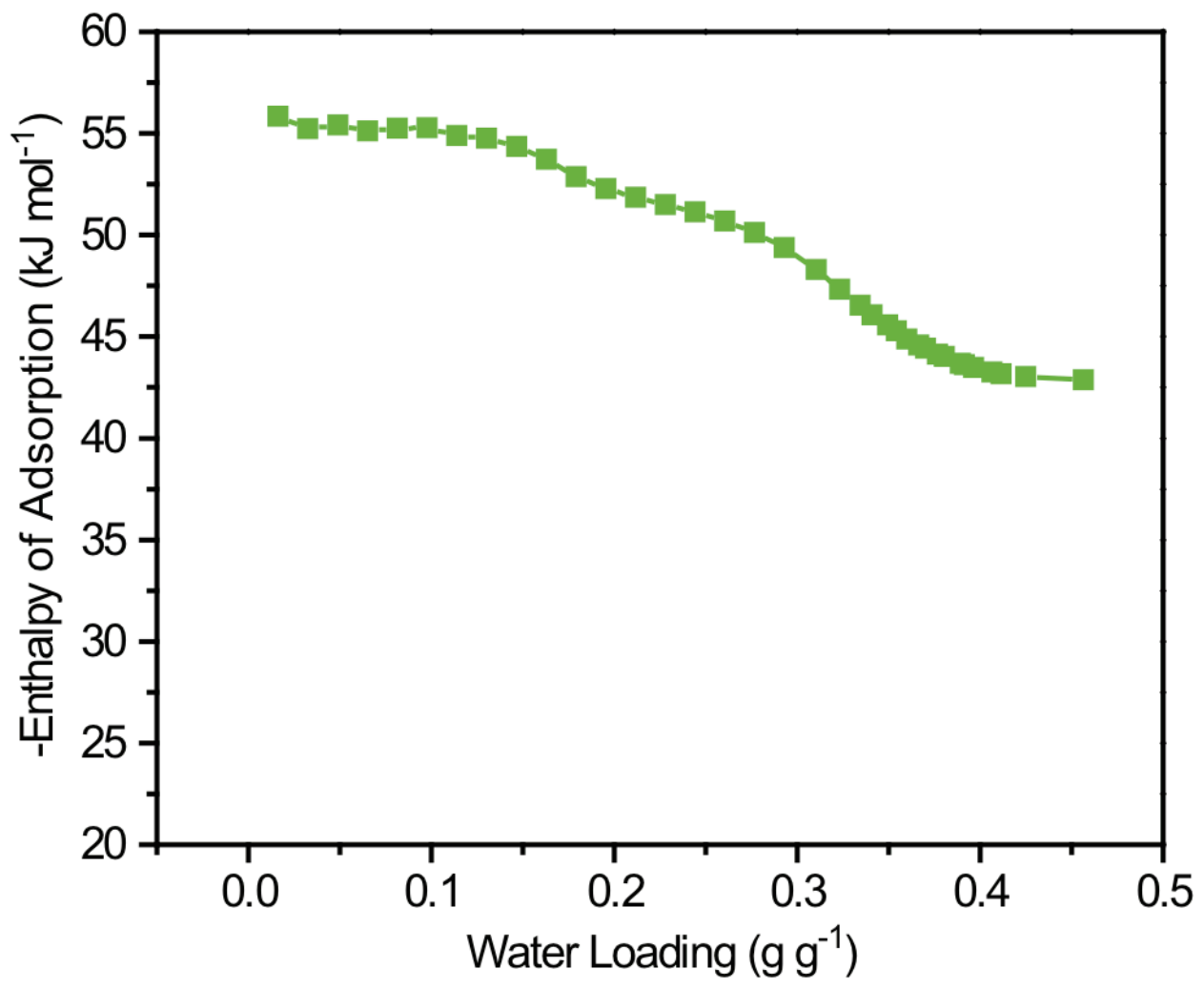

Figure S8. The enthalpy of adsorption for water in $\mathrm{Ni}_{2} \mathrm{Cl}_{2} \mathrm{BBTA}$ versus loading. 


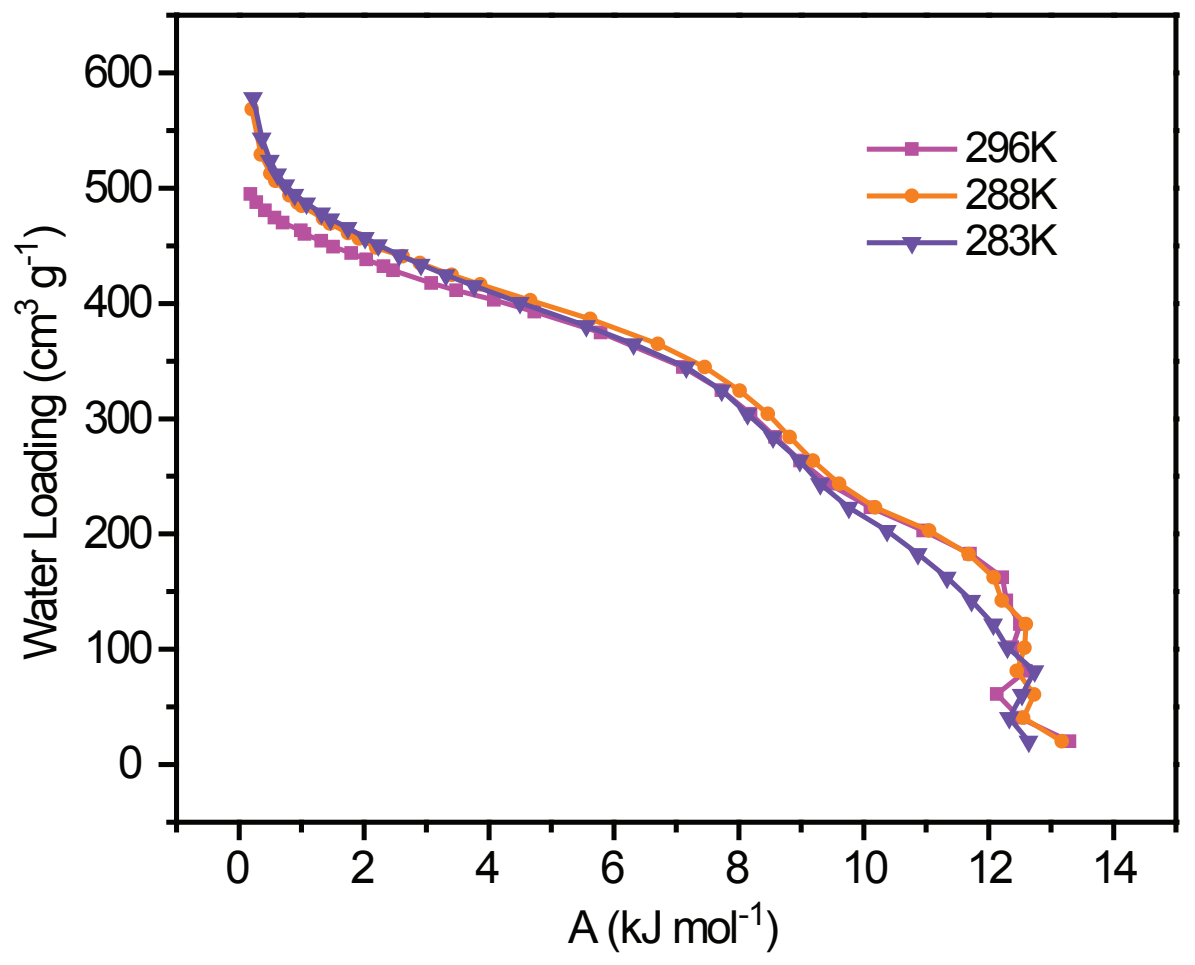

Figure S9. Characteristic curves for water vapor adsorption in $\mathrm{Ni}_{2} \mathrm{Cl}_{2} \mathrm{BBTA}$ calculated using the isotherms at $296 \mathrm{~K}$ (purple squares), $288 \mathrm{~K}$ (orange circles), and $283 \mathrm{~K}$ (blue triangles). The characteristic curve is temperature invariant, justifying its usage to calculate isotherms at other temperatures relevant for AHPs. 


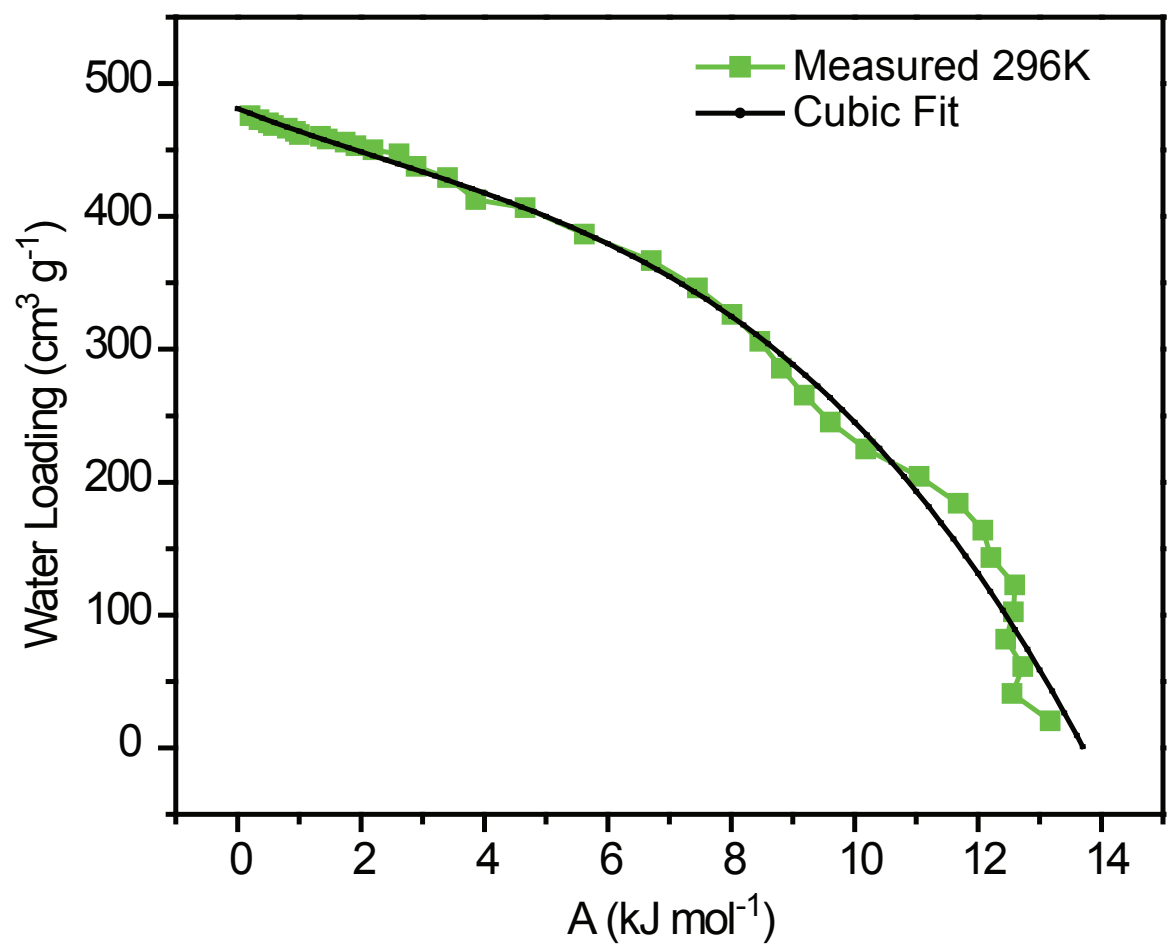

Figure S10. Cubic least-squares fit to the characteristic curve measured at $296 \mathrm{~K}$. The black line is according to the equation $W=-0.1869 A^{3}+1.332 A^{2}-18.23 A+481.2$. The $R^{2}$ value for the fit was 0.988 The fitted equation was used to calculate loading at temperatures and pressures relevant for AHPs. 


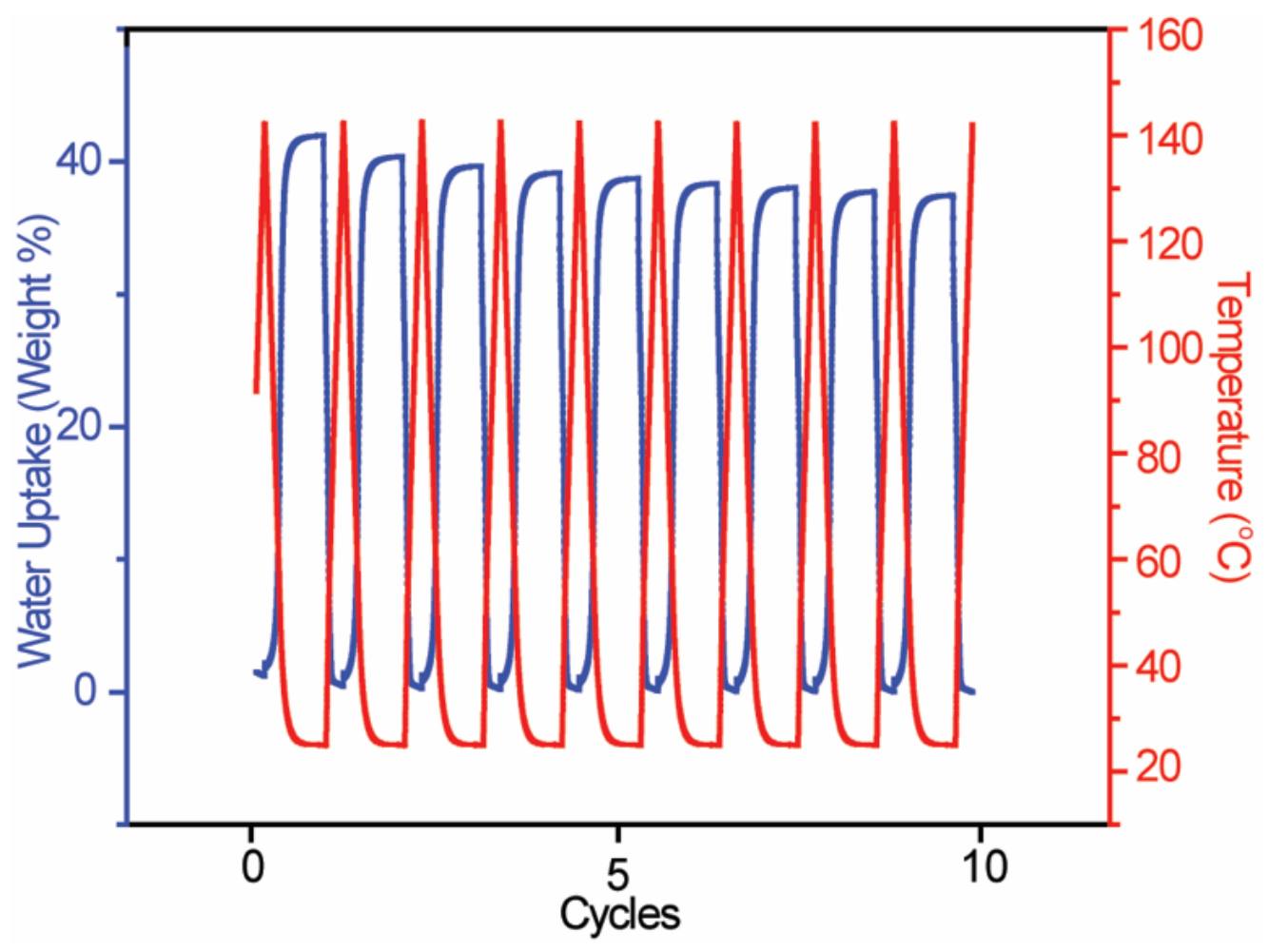

Figure S11. Temperature-swing water cycling of $\mathrm{Ni}_{2} \mathrm{Cl}_{2} \mathrm{BBTA}$ at a constant water vapor pressure of $4.76 \mathrm{mmHg}$. 


\section{References}

[1] Liao P-Q, Li X-Y, Bai J, He C-T, Zhou D-D, Zhang W-X, et al. Drastic enhancement of catalytic activity via post-oxidation of a porous Mnll triazolate framework. Chem - A Eur J 2014;20:11303-7. doi:10.1002/chem.201403123.

[2] Liao P-Q, Chen H, Zhou D-D, Liu S-Y, He C-T, Rui Z, et al. Monodentate hydroxide as a super strong yet reversible active site for $\mathrm{CO}_{2}$ capture from high-humidity flue gas. Energy Environ Sci 2015;8:1011-6. doi:10.1039/C4EE02717E.

[3] Rieth AJ, Dincă M. Controlled Gas Uptake in Metal-Organic Frameworks with Record Ammonia Sorption. J Am Chem Soc 2018;140:3461-6. doi:10.1021/jacs.8b00313.

[4] de Lange MF, van Velzen BL, Ottevanger CP, Verouden KJFM, Lin L-C, Vlugt TJH, et al. Metal-Organic Frameworks in Adsorption-Driven Heat Pumps: The Potential of Alcohols as Working Fluids. Langmuir 2015;31:12783-96. doi:10.1021/acs.langmuir.5b03272.

[5] Cadiau A, Lee JS, Damasceno Borges D, Fabry P, Devic T, Wharmby MT, et al. Design of Hydrophilic Metal Organic Framework Water Adsorbents for Heat Reallocation. Adv Mater 2015;27:4775-80. doi:10.1002/adma.201502418.

[6] De Lange MF, Verouden KJFM, Vlugt TJH, Gascon J, Kapteijn F. Adsorption-Driven Heat Pumps: The Potential of Metal-Organic Frameworks. Chem Rev 2015;115:12205-50. doi:10.1021/acs.chemrev.5b00059. 